\title{
Isolated Sphenoiditis, Hidden Cause of Headache
}

\author{
Dr. Saad Y. Sulaiman \\ Department of Surgery, Nineveh College of Medicine, Nineveh University, Mosul, Iraq. \\ Correspondence: Saad Y. Sulaiman. saadsulaiman966@gmail.com
}

(Ann Coll Med Mosul 2019; 41 (1):36-42).

Received: $6^{\text {th }}$ Nov. 2018; Accepted: $16^{\text {th }}$ Jun. 2019.

\begin{abstract}
Background: Many patients present to otorhinologists daily complaining of headache due to rhinosinusitis which generally has a specific findings. Nonetheless, isolated sphenoiditis is a rare type of sinusitis, but associated with more serious complications due to its contiguity with vital intracranial structures, and is usually associated with non-specific findings that may be missed as a cause of headache.

Objectives: To highlight cases with headache due to isolated sphenoiditis that present with non-specific signs and symptoms of sinusitis, and to discuss the best methods of diagnosis and treatment to avoid serious complications.

Patients and methods: A case series study of 27 patients (21 males, 8 females) aged between 18-32 years-old (mean age 25 years old), were evaluated during the period between June 2015 and December 2017 in the author's private clinic at PAR Hospital, Erbil, Iraq. Those patients were misdiagnosed as cases of primary headache (migraine or tension-type headache). The diagnosis of isolated sphenoiditis in those patients was based on clinical findings, nasal endoscopy and it was proved by computerized tomography scan.

Results: The study was performed on adult patients, half of them were between 24-28 years-old, with a male to female ratio of $7: 3$. Headache was the presenting symptom with minimal expression of other symptoms of sinusitis, i.e.; nasal obstruction in 10 patients (37\%), postnasal discharge in 5 patients (18.5\%), visual symptoms in 3 patients (11\%) and sneezing and itching in 6 patients $(22 \%)$. Nasal endoscopic findings were negative in 5 patients (18.5\%), while septal deviation was noted in 14 patients (52\%), concha bullosa in 1 patient (3.7\%), postnasal discharge in 5 patients (18.5) and granular pharyngitis in 10 patients (37\%). Computerized tomography scanning of the paranasal sinuses was performed for all patients and proved the diagnosis of isolated sphenoiditis. Headache was relieved by medical treatment in 22 patients (81.5\%). Five patients (18.5\%) required surgical treatment.

Conclusion: Although it is uncommon, isolated sphenoiditis must be suspected in patients with headache. It is a potentially dangerous disorder due to the contiguity of the sinus with vital neuro-vascular structures. Therefore, ENT specialists must be alert of this rare condition and radiological examination of paranasal sinuses should always be performed in prolonged and intractable cases of headache. Computerized tomography scan is the best tool in diagnosis and follow up of such cases.
\end{abstract}

Keywords: Isolated sphenoiditis, headache, sphenoid sinus.

$$
\begin{aligned}
& \text { إلتهاب الجيب الأنفي الوتدي المنفرد، سبب مخفي للصداع } \\
& \text { فرع الجراحة، كلية طب نينوى، جامعة نينوى، الموصل، العراق }
\end{aligned}
$$

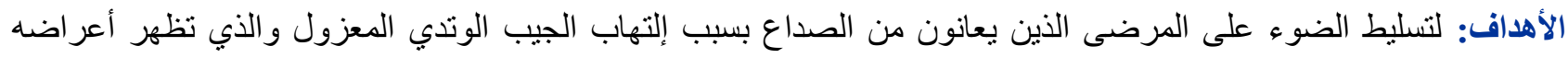

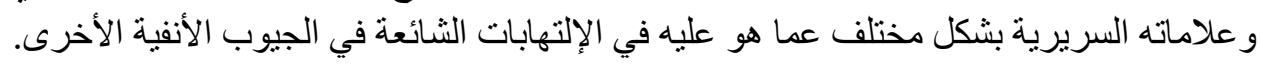




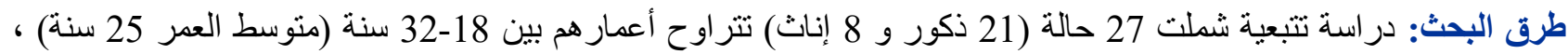

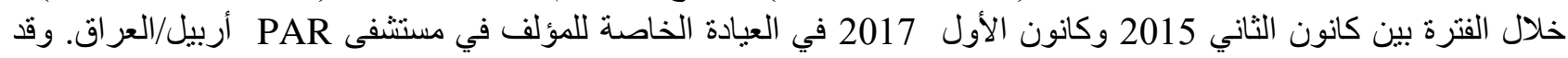

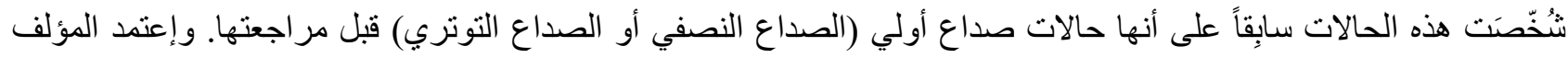

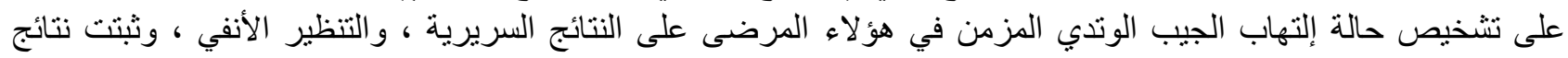
التشخيص عن طريث التصوير الثعاعي المقطعي.

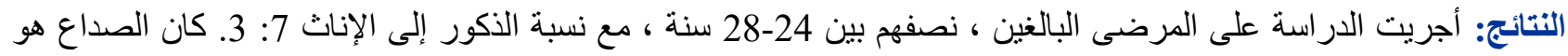

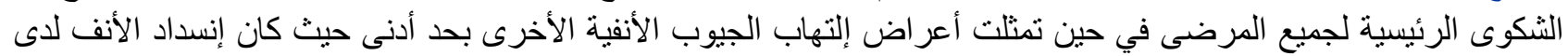

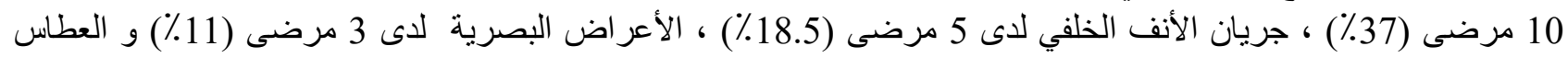

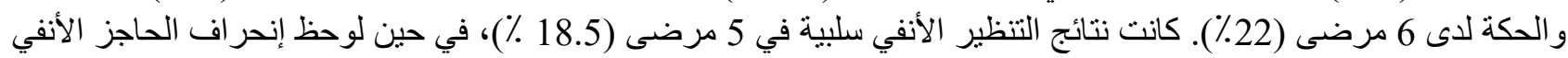

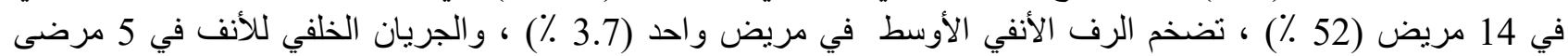

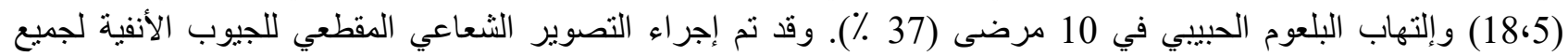

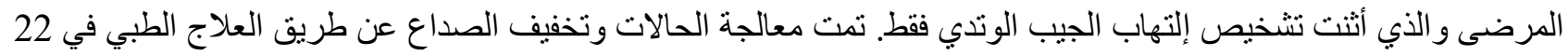

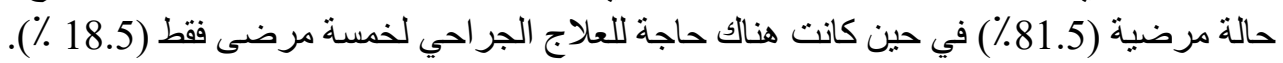

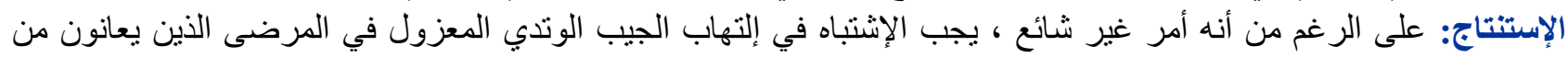

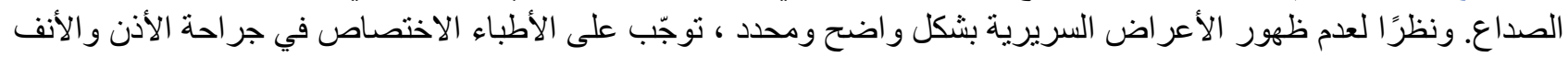

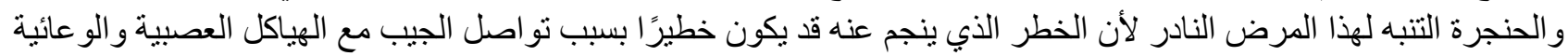

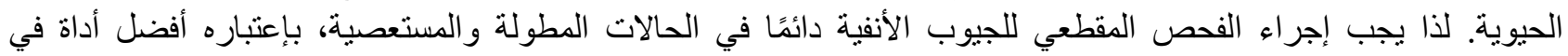
التتخيص و المتابعة.

الكلمات المفتاحية: إلتهاب الجيب الوتدي، الصداع ، الجيوب الوتدية.

\section{INTRODUCTION}

TT he sphenoid sinuses occupy the body of the sphenoid bone at the junction of the anterior and middle cranial fossae in the skull base and drain into the sphenoethmoidal recesses. These sinuses develop asymmetrically and are separated by the intersinus bony septum ${ }^{1}$. Sphenoid bone pneumatization starts early at the age of 3 years and extends toward the sella turcica by the age of 7 years to reach its final form of development in the mid-teens ${ }^{2,3}$. Each sphenoid sinus drains through a single ostium: this ostium is classically located $7 \mathrm{~cm}$ from the base of the columella at an angle of $30^{\circ}$ with the floor of the nose in a parasagittal plane, and this usually corresponds to a location halfway up the anterior wall of the sinus. Endoscopically, the posteroinferior end of the superior turbinate points superiorly and medially toward the sphenoid sinus ostium. This represents an important landmark during endoscopic sinus surgery. ${ }^{1}$ (Fig. 1)

Chronic sphenoid rhinosinusitis is an inflammatory diseases of the sphenoid sinus, which may persist over a period of 12 weeks. It is a different entity from other types of rhinosinusitis because patient may present with headache, visual loss or diplopia while nasal obstruction or nasal discharge may or may not be present. ${ }^{4}$

In most cases of sphenoid sinusitis, symptoms do not appear early or are non-specific and this makes the diagnosis difficult ${ }^{5}$. Nonetheless, early and accurate diagnosis is of utmost importance due to the anatomical relation of the sinus with vital neuro-vascular structures including optic nerve and chiasm, cavernous sinuses, and cranial nerves adjacent to the sphenoid sinus. Delay in proper initiation of treatment may result in catastrophic consequences. It is commonly believed that due to unusual and vague symptoms of sphenoid sinusitis, patients are usually not referred to the otolaryngologist immediately, but instead are initially treated by other specialists, thus adding further delay to the diagnosis ${ }^{5,6}$. 


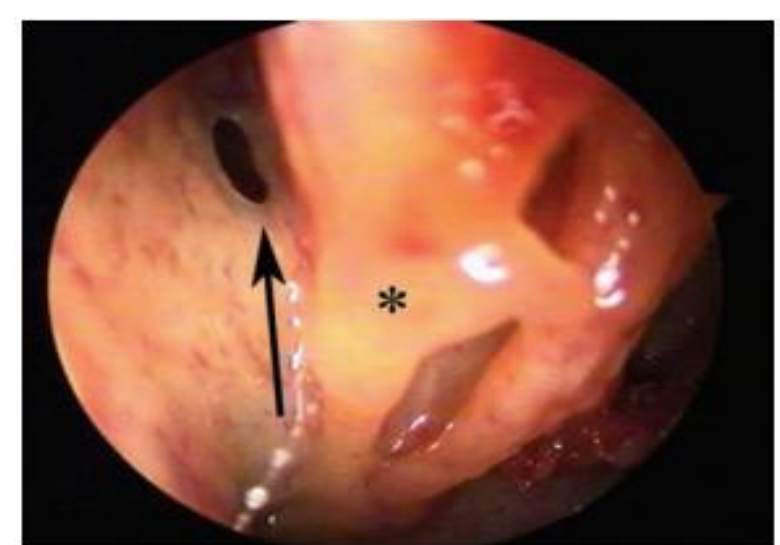

Figure 1: The left sphenoid sinus ostium is found superomedial (arrow) at the tail of the superior turbinate (asterisk). ${ }^{1}$

\section{PATIENTS AND METHOD}

In this case series study, 27 patients including (21 males and 8 females) were included and aged between 18-32 year-old (with a mean age of 25 years). They were evaluated during the period between June 2015 to December 2017 in the author's private clinic at PAR Hospital, Erbil, Iraq.

All patients presented with headache of various intensity. It was mostly localized on the vertex. Only ten patients (37\%) were having nasal obstruction, and five patients (18.5\%) had postnasal discharge. The duration of symptoms ranged from three months to one year. None of the patients were diabetic or hypertensive. Anterior rhinoscopy and endoscopic examination (using rigid $2.5 \mathrm{~mm} 0^{\circ}$ nasal endoscope) showed no evidence of sinonasal infection in 17 patients (63\%), but septal deviation was evident in 14 patients $(52 \%)$ and was severe in two cases. Coronal and axial computerized tomography (CT) scans of paranasal sinuses were performed for all patients, and proved the diagnosis of isolated sphenoiditis. The presence of other sinus pathology was an exclusion criterion. All patients were managed as cases of primary headache (migraine or tension headache) before their presentation to the author's clinic. The patient's history, examination, endoscopic findings and CT scan / MRI findings were registered for proper analysis. All patients were given trials of treatment with oral antibiotics. Fluoroquinolones antibiotics including Factive ${ }^{\circledR}$ (Gemifloxacin) 320 mg., Avalox ${ }^{\circledR}$ or Muxava $^{\circledR}$ (Moxifloxacine) 400 mg., or Tavanic ${ }^{\circledR}$ (levofloxacine) $500 \mathrm{mg}$. were used in the treatment in this study although most patients were on irregular self-medication with Amoxicillin or Amoxiclav that was not effective. Any one of these Fluoroquinolones antibiotics was given once daily for 10 days in association with Rhinocort ${ }^{\circledR}$ Aqua nasal spray (Budesonide 64 micrograms) in a dose of $256 \mathrm{mcg}$ per day administered as 2 sprays in each nostril once daily for two weeks.

In the majority (22 patients), headache was relieved by medical treatment within one week without analgesics. Five patients required Endoscopic Sinus Surgery, when there was no response to medical treatment after 6 weeks and those were admitted to PAR hospital and the operation was performed under general hypotensive anaesthesia.

\section{OPERARIVE PROCEDURE}

Before starting the operation, neurosurgical patties soaked with mixture of 2 ampules of adrenaline (each ampule contain $1 \mathrm{ml}$, which is equivalent to 1 $\mathrm{mg}$ of adrenalin) and xylometazoline hydrochloride $0.1 \%(10 \mathrm{ml})$, and these patties were placed between the middle turbinate and the nasal septum to decongest the nasal mucosa. Furthermore, the middle turbinate was delicately dislocated laterally to enlarge the space between it and the nasal septum, and to create an adequate surgical pathway. The endoscope is then introduced and directed upward along the roof of the choana, just posterior to the superior turbinate, until it reaches the sphenoid sinus ostium. In two cases, the sphenoid ostium was widened using mushroom biting forceps and a sample from sphnoid sinus content was sent for biopsy and culture and sensitivity. One of them (3.7\%) proved to be fungal sinusitis after histologic examination and culture of sphenoid sinus mucin.

In three cases (11\%), severe septal deviation obscured visualization of the sphenoethmoidal recess and they got good response after septoplasty without widening of sphenoid sinus ostium.

The follow up period varied according to the time of presentation of each case within the period of the study. Therefore 10 patients (37\%) had been followed up for more than 12 months, while 13 patients $(48 \%)$ had been followed up for 6-12 months and 4 patients (14.8\%) for 3-6 months. 


\section{RESULTS}

All the selected patients were adults ( $>18$ year old) and nearly half of them were between the age of 24-28 year-old. (Fig. 2)

In this study, males are more affected than females. (Fig. 3)

The duration of symptoms was mainly between 6 and 12 months. (Fig. 4)

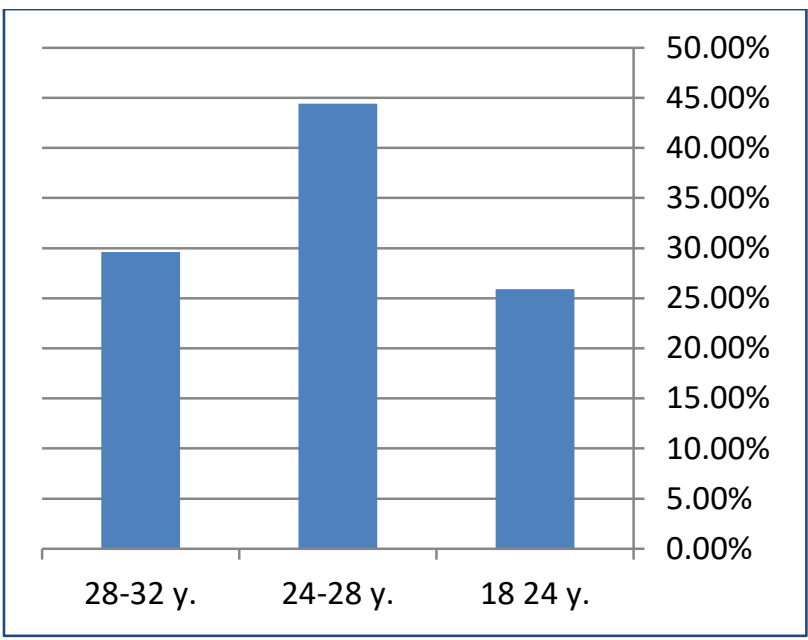

Figure 2: Age distribution.

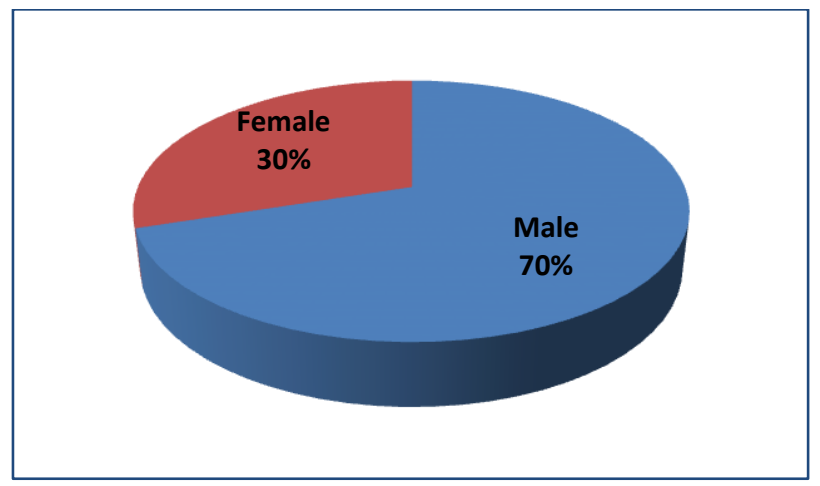

Figure 3: Sex distribution.

3-6 months $\square$ 6-12 months $\square>12$ months

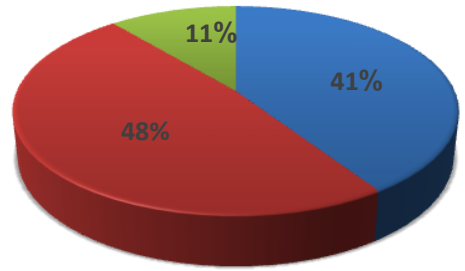

Figure 4: Duration of symptoms.
Headache was the presenting symptom in all patients. The pain described as dull, intermittent, sometimes interfered with sleep, and was not relieved by simple analgesics. It was associated with nasal obstruction (mild to moderate) in 10 patients $(37 \%)$, and postnasal discharge in five patients $(18.5 \%)$. Visual symptoms were noted in three patients $(11 \%)$. The visual symptoms occurred mostly in the form of blurring of vision. Sneezing and itching were positive in six patients (22\%) (Fig. 5).

All patients underwent coronal and axial CT scanning of the paranasal sinuses. Magnetic resonance imaging (MRI) was performed in two patients $(7.4 \%)$ which had been requested by the neurologist before they were presented to the author.

Endoscopic assessment was performed for all patients. In five patients (18.5\%), endoscopy was not significant. In 14 patients (52\%), there was septal deviation. Middle turbinate enlargement at the same side of sphenoiditis (proved by CT scan to be concha bullosa as shown in Fig. 6) was seen in 1 patient (3.7\%). Postnasal discharge was seen in 5 patients (18.5\%) and chronic granular pharyngitis was detected in 10 patients (37\%).

(Fig. 7)

In all cases, only unilateral sphenoid sinus affected with nearly equal incidence (Table 1) (Fig. 8).

Computerized tomography scan in all cases and brain MRI (that obtained earlier during a neurologic evaluation in only 3 patients) showed complete opacification or mucosal thickening of the affected sphenoid sinuses (Figures 8-9).

In 22 patients $(81.5 \%)$, headache was relieved by medical treatment within one week without analgesics. Five patients (18.5\%) failed to respond to medical treatment over a period of 8 weeks and required endoscopic sinus surgery involving widening of sphenoid sinus ostium and biopsy, with or without septoplasty. One of them proved to be fungal sinusitis after histologic examination and culture of sphenoid sinus mucin.

Twenty patients (74\%) were cured after medical and/or surgical treatment with no recurrence within 30 months. Signs and symptoms of recurrence were recorded within 3 to 30 months. The followup results shown in the Table 2. 


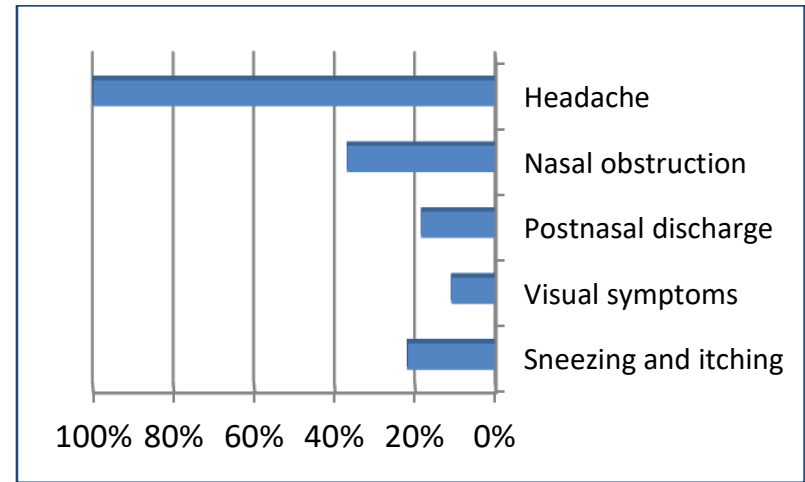

Figure 5: Symptoms.

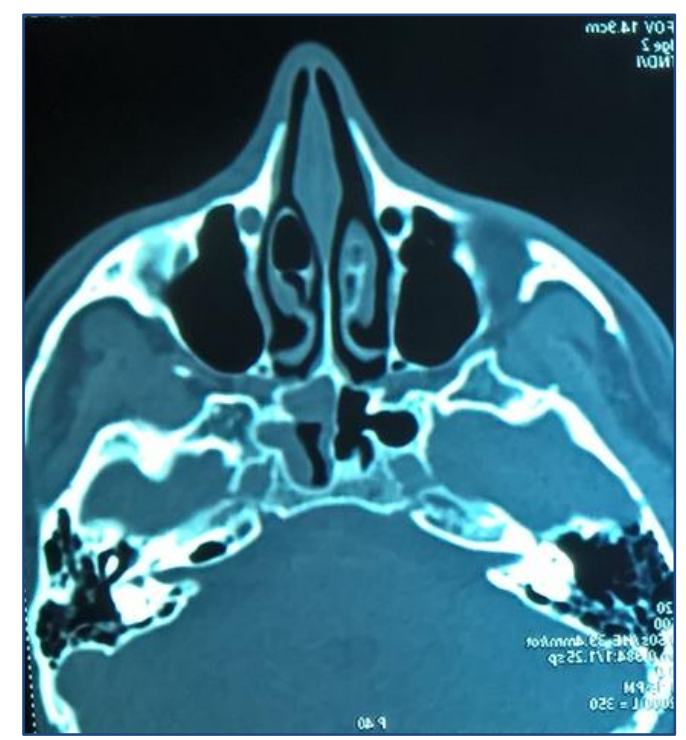

Figure 6: Right sphenoiditis with Rt. concha bullosa.

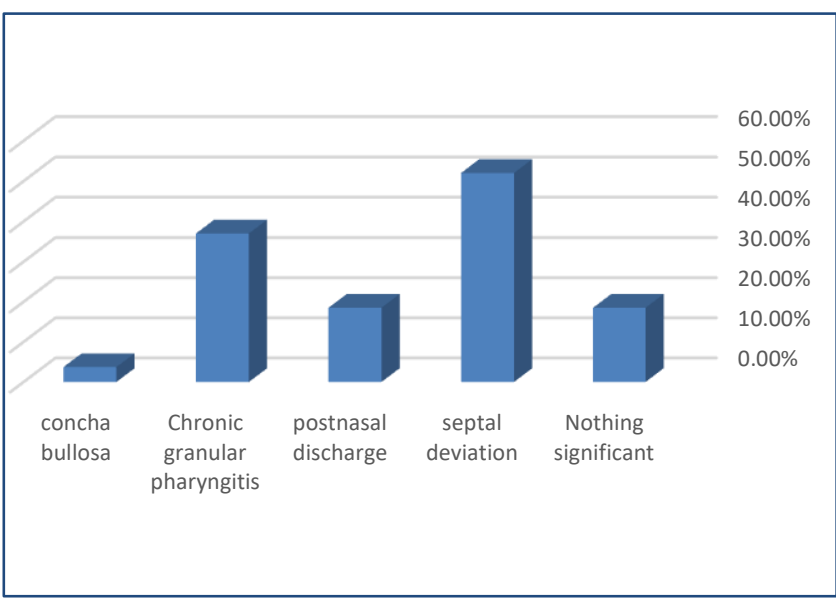

Figure 7: Clinical findings

Table 1: Affected side.

\begin{tabular}{lc}
\hline Rt. sphenoiditis & 13 patients (48\%) \\
\hline Lt. sphenoiditis & 14 patients (52\%) \\
\hline
\end{tabular}

A

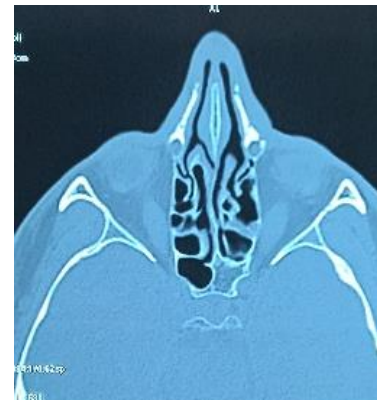

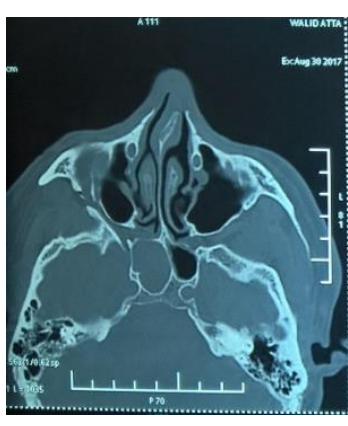

B
Figure 8: CT scan showing (A) Left sphenoiditis, (B) Right sphenoiditis.

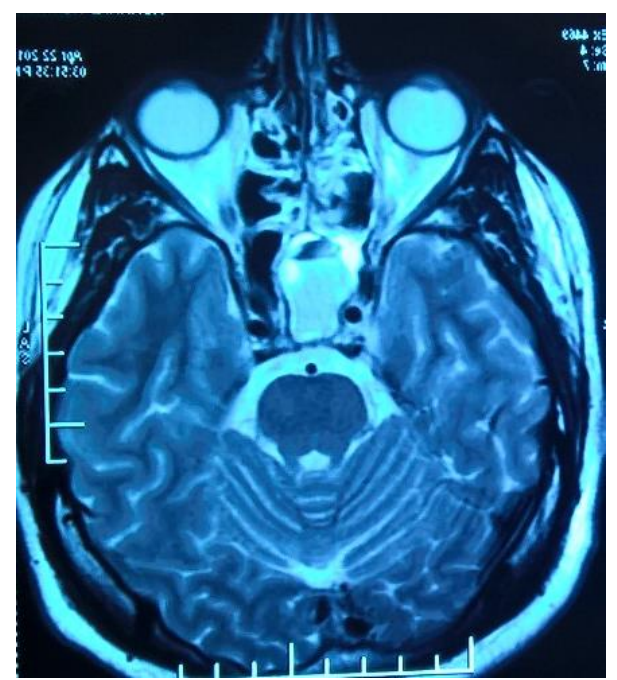

Figure 9: MRI showing left sphenoiditis.

Table 2: Results of follow-up.

\begin{tabular}{|c|c|c|c|}
\hline \multirow[b]{2}{*}{$\begin{array}{c}\text { Follow-up } \\
\text { time } \\
\text { (months) }\end{array}$} & \multirow[b]{2}{*}{$\begin{array}{l}\text { No. of } \\
\text { cases } \\
(\%)\end{array}$} & \multicolumn{2}{|c|}{ Recurrence } \\
\hline & & $\begin{array}{l}\text { No. of } \\
\text { patients } \\
\text { with no } \\
\text { signs of } \\
\text { recurrence }\end{array}$ & Recurrence events \\
\hline 3-6 m. & $\begin{array}{c}4 \\
(14.8 \%)\end{array}$ & 3 & $\begin{array}{c}\text { One patient came } \\
\text { back with only } \\
\text { postnasal discharge } \\
(3.7 \%)\end{array}$ \\
\hline 6-12 m. & $\begin{array}{c}13 \\
(48 \%)\end{array}$ & 10 & $\begin{array}{l}\text { Three patients came } \\
\text { back with mild } \\
\text { headache but CT } \\
\text { scan showed no } \\
\text { recurrence of } \\
\text { sphenoid sinusitis } \\
(11 \%)\end{array}$ \\
\hline $\begin{array}{c}\text { More than } \\
12 \mathrm{~m} .\end{array}$ & $\begin{array}{c}10 \\
(37 \%)\end{array}$ & 7 & $\begin{array}{l}\text { Three patients came } \\
\text { back with recurrent } \\
\text { attacks of nasal } \\
\text { obstruction, } \\
\text { rhinorrhea, sneezing } \\
\text { and sore throat with } \\
\text { mild headache after } \\
\text { exposure to smokes, } \\
\text { irritant odor or dusts } \\
\text { that responded } \\
\text { quickly to antiallergic } \\
\text { drugs and simple } \\
\text { analgesics (26\%). }\end{array}$ \\
\hline
\end{tabular}




\section{DISCUSSION}

Headache is a common complaint that otolaryngologists evaluate in their clinics. Therefore, it is necessary to be proficient in differentiating between headaches of both sinonasal and non-sino-nasal origins. ${ }^{7}$

Isolated sphenoid sinus diseases are rare and account for approximately $2-3 \%$ of all sinus diseases $^{8}$. The sphenoid sinus is lined by pseudostratified ciliated columnar epithelium with fewer mucous secreting cells as compared to other paranasal sinuses. This causes less drainage problems and may explain the relative rarity of isolated sphenoid sinus infection ${ }^{9}$. In addition, the deep location of the sphenoid sinus is suggested to make it less accessible to infectious agents ${ }^{6}$.

All patients in this study presented with headache of various intensity. This is comparable with other studies, as it was the presenting symptom in sphenoiditis in over $80 \%$ of cases in Charakorn $\mathrm{N}$ and Snidvongs $\mathrm{K}^{4}$ and $77.7 \%$ in Marcolini T. R et. al. ${ }^{10}$

In this study, the majority of cases of sphenoid sinusitis were in males. This is comparable with Chen $\mathrm{L}$ et $\mathrm{al}$ and Sieskiewicz $\mathrm{A}$ et al as it was also more in males ${ }^{11,5}$. However, in Dilci $A$ et al, it was more in females ${ }^{12}$. This may be related to the degree of sphenoid sinus pneumatization because chronic sinusitis is known to be associated with increased paranasal sinus pneumatization ${ }^{13}$. This may explain the predominance in male cases because males had significantly larger sinus volumes than females, although older patients demonstrated a significantly lower volume of sphenoid sinuses ${ }^{14}$. Moreover, racial differences and genetic factors also play a role in development of sphenoid sinus ${ }^{15,16}$. This may explain the difference between different studies as the samples of patients differ in age, sex and ethnic identity.

As far as the duration of symptoms were more than three months at the time of presentation, these cases were considered as chronic type of sinusitis according to European position paper on rhinosinusitis and nasal polyps $2012^{17}$. Isolated sphenoiditis differs from other types of rhinosinusitis because patients may not have nasal obstruction or nasal discharge and only present with headache, visual disorders and/ or diplopia ${ }^{4}$.
Headache was the main symptom and this complaint had been present before the diagnosis was established. The delay period was between 3 and 12 months in $89 \%$ of cases, while in Sieskiewicz A et al it was $(75.8 \%)^{5}$. Delayed and misdiagnosis may occur due to its nonspecific symptoms $^{18}$.

Patients with sphenoiditis rarely experience the common nasal symptoms of sinusitis which include nasal obstruction, nasal discharge, postnasal drip, hyposomia and facial pain ${ }^{19}$. Nasal obstruction or congestion is the presenting symptom in other types of sinusitis, which is although less frequent in chronic sinusitis, but still is the most prevalent individual symptom $(93.5 \%)^{20}$. In our study, nasal obstruction was identified in $37 \%$ of cases, and this is comparable with Marcolini TR et al, as it was $32.6 \%{ }^{10}$.

In rhinosinusitis, anterior or posterior nasal discharge is considered one of the major symptoms ${ }^{21}$. This is not always the case in isolated sphenoiditis due to the fewer mucous secreting cells in the lining of sphenoid sinus as compared to other paranasal sinuses ${ }^{9}$. In this study, postnasal discharge was identified in $18.5 \%$ of patients, while in Marcolini, et al. as it was present in $13 \%$ of cases ${ }^{10}$ and in $\mathrm{Kim}$, et al it was present in $21 \%$ of cases ${ }^{22}$

Features of allergic rhinitis were detected in $22 \%$ of patients in our study in the form of nasal itching, sneezing and rhinorrhea. In a study by Berrettini S. et al, sinusitis is seen in $67.5 \%$ of the allergic patients ${ }^{23}$. This is due to the oedematous and polypoidal changes that affect the mucosa in the sphenoethmoidal recess which impede drainage of sphenoid sinus and cause infection ${ }^{8,24}$.

Early diagnosis is important to avoid serious complications due the anatomical relation of the sinus to the vital intracranial and orbital structures, to which infection may easily spread ${ }^{19}$. In our study, visual symptoms were noted in $11 \%$ of patients, while in Ni D, Qi F et al, it was evident in $50 \%$ of cases ${ }^{25}$.

This depends on the chronicity of infection. Therefore, patients with chronic sinusitis may look less severely ill than others with acute exacerbations of infection ${ }^{9}$.

Nasal endoscopy is useful for diagnosis, but it was normal in $18.5 \%$ of patients in this study. However, in Fountoulakis $\mathrm{E}$ et al it was normal in 
$60 \%$ of cases ${ }^{26}$, while in Sieskiewicz A et al it was normal in $31.2 \%{ }^{5}$.

Consequently, CT scan is the only modality that can consistently detect isolated sphenoiditis ${ }^{26}$. It can determine the pathological characteristics of the mucosa and bone of each of the affected paranasal sinuses in general. Therefore it can differentiate inflammatory disease from neoplasm and bacterial from fungal infections. MRI is only required when there is suspicion of intracranial or orbital extension to exclude any associated intracranial pathology 16,27 . In this study, all diseases that affect the sphenoid sinus were inflammatory in origin.

\section{CONCLUSIONS}

Although it is uncommon, isolated sphenoiditis must be suspected in patients with headache. Other symptoms of paranasal sinusitis are not always seen in those patients and normal endoscopic examination could not completely exclude the disease. Therefore, ENT specialists must be alert of this rare but still potentially dangerous disorder due to the contiguity of the sinus with vital neuro-vascular structures. CT scan of paranasal sinuses should always be performed in prolonged and intractable cases of headache, as it is the best tool in diagnosis.

\section{REFERENCES}

1. Sargi ZB, Casiano RR. Surgical anatomy of the paranasal sinuses. In: Kountakis SE, Onerci M, eds. Rhinologic and Sleep Apnea Surgical Techniques. Berlin, Heidelberg, Germany: Springer; 2007:17-26.

2. Rice DH, Schaefer SD, Anatomy of the Paranasal Sinuses. In: Rice DH, Schaefer SD (2004). $3^{\text {rd }}$ ed Endoscopic Paranasal Sinus Surgery. Lippincott Williams \& Wilkins.

3. Van Cauwenberge $P$, Sys L, De Belder $T$ et al. Anatomy and physiology of the nose and the paranasal sinuses. Immunol Allergy Clin North Am 2004;24(1):1-17.

4. Charakorn N, Snidvongs K. Chronic sphenoid rhinosinusitis: management challenge. J Asthma Allergy. 2016; 9: 199-205.

5. Sieskiewicz A, Lyson T, Olszewska E, Chlabicz M, Buonamassa S, Rogowski M. Isolated sphenoid sinus pathologies- the problem of delayed diagnosis. Med Sci Monit. 2011; 17(3): CR179-CR183.

6. Celenk F, Gulsen S, Gonuldas B, et al. Isolated sphenoid sinus disease: an overlooked cause of headache. Journal of Cranio-Maxillo-Facial Surgery 2015;43 (9): 19141917.

7. Levine HL, Setzen M, Cady RK, Dodick DW, Schreiber $\mathrm{CP}$, Eross EJ, Blumenthal HJ, Lumry WR, Berman GD, Durham PL. An otolaryngology, neurology, allergy, and primary care consensus on diagnosis and treatment of sinus headache. Otolaryngol Head Neck surg. 2006 Mar; 134(3):516-23.

8. Yu-Hsing Lin, Sheen-Yie Fang, Hsu-Cheuh Ho. Isolated Sphenoid Sinus Disease: Analysis of 11 Cases. TZU CHI MED J September 2009, Vol 21, No. 3.
9. Tan HK, Ong YK. Acute isolated sphenoid sinusitis. Ann Acad Med Singapore. 2004; 33: 656-659.

10. Marcolini TR, Safraider MC, Socher JA, Lucena GO. Differential diagnosis and treatment of isolated pathologies of the sphenoid sinus: retrospective study of 46 cases. Int Arch Otorhinolaryngol 2015; 19: 124-129.

11. Chen L, Jiang L, Yang B, Subramanian PS. Clinical features of visual disturbances secondary to isolated sphenoid sinus inflammatory diseases. BMC Ophthalmol. 2017 Dec. 6;17(1):237.

12. Dilci A, Bilac Ö, Giritli E. Isolated sphenoid sinus pathology: retrospective analysis of 7 cases, Osmangazi Journal of Medicine 20184;0 (1):83-89.

13. MJ Marino, CA Riley, EL Wu, JE Weinstein, ED McCoul. Are Chronic Rhinosinusitis and Paranasal SinusPneumatization Related?.Sinusitis2016;1(1),92-98.

14. Cohen O, Warman M, Fried M, Shoffel Havakuk H, Adi $\mathrm{M}$, et al. Volumetric analysis of the maxillary, sphenoid and frontal sinuses: A comparative computerized tomography based study. Auris Nasus Larynx 2017;45(1): 96-102.

15. Al-Abri R, Bhargava D, Al-Bassam W, Al-Badaai $Y$, Sawhney S. Clinically significant anatomical variants of the paranasal sinuses. Oman Medical Journal. 2014;29(2):1103.

16. Kikuchi R, Toda M, Tomita T, Ogawa K, Yoshida K. Analysis of sphenoid sinus lateral pneumatization for endonasal endoscopic surgery. Surg Neurol Int. 2015 Oct $27 ; 6: 166$

17. Fokkens WJ, Lund VJ, Mullol J, Bachert C, Alobid I, Baroody F, et al. EPOS 2012: European position paper on rhinosinusitis and nasal polyps 2012. A summary for otorhinolaryngologists. Rhinology. 2012; 50: 1-12.

18. Alazzawi S, Shahrizal T, Prepageran N, Pailoor J. Isolated sphenoid sinus lesion: A diagnostic dilemma. Qatar Med J 2014 Jun16; 2014(1):57-60.

19. Kordrostami P, Parmar A. Isolated Sphenoiditis Presenting with Abducens Nerve Palsy. Ann Otolaryngol Rhinol 2014;1(3): 1014

20. Abdalla. S, Alreefy $H$, Hopkins C. Prevalence of sinonasal outcome test (SNOT-22) symptoms in patients undergoing surgery for chronic rhinosinusitis in the England and Wales National prospective audit. Clin. Otolaryngol. 2012; 37, 276-282.

21. Fokkens W, Lund V, Mullol J; European Position Paper on Rhinosinusitis and nasal Polyps group. European Position Paper on Rhinosinusitis and nasal Polyps 2007. Rhinol Suppl 2007; 20: 1-163.

22. Kim SW, Kim DW, Kong IG, Kim DY, Park SW, Rhee $\mathrm{CS}$, et al: Isolated sphenoid sinus diseases: report of 76 cases. Acta Otolaryngol 2008 Apr;128(4): 455-459,

23. Berrettini $S$, Carabelli $A$, Sellari-Franceschini S, Bruschini L, Abruzzese A, Quartieri F, Sconosciuto F. Perennial allergic rhinitis and chronic sinusitis: correlation with rhinologic risk factors. Allergy. 1999 Mar;54(3):242-8.

24. Slavin RG. Sinusitis in adult and its relation to allergic rhinitis, asthma, and nasal polyps. J Allergy Clin Immunol. 1988 Nov;82 (5 pt 2): 950-6.

25. Ni D, Qi F, Xu C. Neurological manifestations of isolated sphenoiditis. Chinese medical journal 81:16 2001 Aug 25 pg 988-90.

26. Fountoulakis E, Chatzakis N, Panagiotaki I, Karatzanis A, Lagoudianakis G, Velegrakis S, Velegrakis G. Isolated sphenoiditis: presentation of 2 cases and review of the literature. Hippokratia. 2011;15(4):383-384.

27. Socher JA, Cassano M, Fiheiro CA, Cassano P, Felippu A. Diagnosis and treatment of isolated sphenoid sinus disease: a review of 109 cases. Acta otolaryngol $2008 \mathrm{sep}$; 128(9). 